\title{
Vital energy coefficient for leading positive changes on the way to sustainable development
}

\author{
Kirill Gerasimov ${ }^{1}$, Maria Skivko $^{1}$, Natalya Lyubavina ${ }^{2}$ \\ ${ }^{1}$ Samara National Research University, 34, Moskovskoye shosse, Samara, 443086, Russian \\ Federation \\ ${ }^{2}$ Togliatti State University, 14, Belorusskaya St., Togliatti, 445667, Russian Federation
}

\begin{abstract}
This paper focuses on such characteristics of leaders that foster the transformation processes. In particular, the paper analyses the coefficient of vital energy as a significant resource for achieving sustainable development goals. Considered in comparison with inefficient energy use as burnout, vital energy emphasizes the importance of life-work balance and the possibility for recharging for leaders. Moreover, the accent is given to the specificity of sustainable development changes that requires, apart from effective solutions, efficient and passionate leaders.
\end{abstract}

\section{Introduction}

Today, in the rapidly changing world with provoking challenges and unexpected obstacles, there is a strong need for successful leaders. Moreover, within the implementation of sustainable discussion in many areas of human life, there is a demand for those leaders who can provide and manage sustainable development goals. This article highlights such characteristics of a modern leader as a level of life energy needed for goal accomplishment and motivating others.

Life energy can be considered an emotional, physical, and intellectual state of an individual that supports its intention to act in the social environment, achieve goals, and perform changes [1]. Life energy constitutes human social and cultural capital and reflects an individual's life satisfaction and emotional stability. As an essential resource for any human activity (together with time, knowledge, and money), life energy facilitates the human's executing plans, self-realization, and joy of life [2]. Efficient manipulation of various resources helps to achieve success in any social activity.

However, there is always a risk of resource depletion; especially, life energy is endangered today by stress and responsibility at work and private life. Those who work in the social sector, mostly with people (healthcare, education, social work), whose task is helping others or protect the minority or oppressed groups, belong to the risk group that spends much more life energy for social communication at work. The activity related to the promotion and motivation for sustainable development and changes can also be referred to the same risk group due to the high involvement of energy and emotions into the workflow.

\footnotetext{
${ }^{*}$ Corresponding author: 270580@bk.ru
} 
The good news is that life energy resource is renewable: it is possible to control life energy consumption and recharge oneself with different physical and mental practices.

In business and management, several approaches determine that leadership competence consists of three criteria: intelligent quotient (IQ), emotional quotient (EQ), and vitality quotient (VQ). IQ defines the intellectual abilities and potential of an individual, EQ refers to the ability to understand and manage own emotions as well as to use them for efficient communication. VQ is considered as an ability to maintain own energy and entrain others. As Pierre Casse denotes, the VQ today is more significant for leaders and change-makers than the other two components. It helps to set and achieve the goals, motivate others, stimulate changes. So, talking about sustainable development goals, it is necessary to mention that those leadership characteristics become more than just essential at the global and local levels.

\section{Vital energy coefficients}

The realization of sustainable development goals would not be possible without successful and encouraging leaders. In industries, science, techno sphere, education, or cultural sector, there is a need for those change-makers who can perform high intellectual ability, high level of emotional intelligence, and the power to bring positive energy to own life and life of others. These qualities are especially demanded in turbulent and insecure times.

Today, the leaders' working routine consists of a plurality of tasks, changing deadlines, and increasing information for processing and analysis. High levels of responsibility and emotional involvement complement this leadership profile. Moreover, digitization created unlimited possibilities for online-communication but expropriated privacy: the all-day online-presence did not leave the space for quietness and unavailability. On the one hand, technological development accelerated the speed of work and increased work efficiency; on the other hand, it endangered the quality of work and lowered personal responsibility. An increase in nervousness and aggression, constant deadline pressure, concentration difficulty, and just stress is some of the possible consequences of this working style and working environment. Individuals regularly need to collect and spend energy; the disbalance negatively affects the physical and mental health.

As Rodionov defines, there are five types of interconnected vital energy today [3]. Physical energy helps at work, and its excess provokes violence, conflicts, or wars. Adversity energy is responsible for the human nervous system and can be controlled or negatively affected by human inventions or influence. Logical vital energy and intellectual energy are high-demandable in industries, politics, and military service. Spiritual energy is supposed to be responsible for the safety and security of society and individuals as well as for the accomplishment of sustainable development goals; it is incorporated into the human culture and cultural values. So, energy accumulation and energy loss are also interconnected: good physical form creates preconditions for spiritual growth or, instead, depression leads to problems with physical health.

Pierre Casse declares that the leadership potential consists of IQ, EQ, and VQ; the ability to critically analyse and the presence of emotional intelligence are not often sufficient to become a successful leader or a good manager [4]. Instead, the vital energy today facilitates mostly those changes that leaders maintain. Vital energy coefficient stimulates, encourages, and motivates for goal achievement and provides the power to improve the life quality. As far as leaders, apart from other activities, are supposed to deal with obstacles and emerging resistance by promoting changes, the high level of VQ can simplify the leadership trajectory and improve the results of their work.

As an innate quality, VQ differs in one personality to another: some people are more active, others are more passive. The higher the vital energy, the more an individual is open 
to changes, aims to improve the social and working environment, and leads the group. It is possible to differentiate the potential and the real VQ. The former refers to the innate vital energy for achieving expected great results, the latter describes the current situation with the vital energy by accomplishing tasks. A high level of real vital energy stimulates the person to achieve professional and personal goals, motivate others, and bring constructive energy to the social and work environment. It positively affects creativity, the decision-making process (and its speed), and an incentive to overcome challenges. However, real vital energy is usually lower than the potential one, which defines the key problem of modern leadership efficiency: It is difficult to make changes without sufficient energy resources.

For increasing the potential vital energy, Casse recommends checking whether the life activity reflects the accomplishment of personal goals and desires. For increasing group motivation and involvement, the leader should use managerial skills to distribute the tasks properly among the team members and emotional intelligence to understand and define the reaction of team members on the workflow. This principle can also be applied to the whole company, community, or nation.

\section{Incorrect use of energy: emotional and professional burnout}

Such characteristics of a leader as flexibility, high potential to inspire and motivate, openness for new opportunities, and new knowledge are very demandable in this rapidly changing world. Especially in the sustainable discussion, there is a need for those leaders who can energize for changes and transformations.

The high speed of life, an increasing list of everyday tasks and challenges, stress, and deadlines do not support or extend the vital energy. Additionally, difficulties at work, interpersonal communication, multitasking work character, limited opportunities for relaxation and free time can worsen any productive activity. It leads to psychological distress, depression, and burnout. It is defined as a syndrome of reduced personal accomplishment, prolonged reaction to chronic job stressors expressed in a depressive mood, nervousness, and loss of motivation $[5,6]$.

Burnout is often a result of job dissatisfaction, lack of control, and uncertainty in the work environment, especially if individual stress experience meets the organizational issues [7]. As a human dimension of sustainability, organizational sustainability is responsible for employees' job satisfaction and positive working climate; increasing competitiveness and variety of demands strengthens the risk of employee burnout [8]. Good management of an encouraging leader can lower this risk if only this leader can deal with his/her own vital energy most productively and efficiently. Various leadership strategies (e.g., coaching, delegation, reconsidering tasks and expectations) can affect the burnout's own level and among employees $[9,10]$.

One of the common problems of contemporary workers, especially among job areas involving people and communication, is emotional burnout. It is understood as increasingly emotional and psychological exhaustion; besides, it can reflect the dynamic character of work or the level of emotional expression, display at work $[11,12]$. It is usually caused by a high range of responsibilities at work, personal crisis, stress, and lack of relaxation. With emotional burnout, professional burnout as an incorrect distribution of life energy for work tasks can destroy the professional motivation and orientation for goal achievement as well as decrease the quality of work [13].

Modern leaders - e.g., social or environmental activists, journalists, youth politicians, or volunteers - quite often meet professional burnout due to the content and character of their work [14]. The reason is usually the intention to motivate, to inspire, to energize that leads to the excessive life energy use: fighting for rights of minorities, promoting different social 
or cultural values, protecting the environment demand not only smart solutions, creativity, and the speaker talent but also a lot of energy and inner power.

As a type of emotional labour, the leader activity can be considered a stressor that ends with burnout [15]. Activist burnout is defined today as a modern burnout type that overwhelms the leader's energy due to the lack of self-care and workflow disbalance [16, 17]. Overwork, conflicts, urgency as well as lack of visible results and social acceptance characterize the activists' work and explain the burnout background. Sometimes, professional role expectations confront the administrative restrictions that result in organizational stress [18]. In the same way, leaders who belong to the potential risk group cannot manage emotions and vital energy by dispersing life energy for everything.

\section{Managing vital energy for sustainable changes}

Sustainability can be explored through the category of balance: resources, investments, and consumer demands. In the same way, social dimension in sustainability, people's resources should also balance physical, emotional, and life energy. On the contrary, the level of burnout as well as of job satisfaction also signifies the social component of sustainability [19]. Therefore, vital energy management should become an integral part of modern leadership competencies. Moreover, in such a complicated global discussion about sustainable changes it is urgent and crucial to implement the strategies and techniques to support encouraging leaders to perform changes. For example, the Heinrich Böll Foundation in Moscow launched an online support project for environmental activists that aims to help lower emotional and professional burnouts with sustainable practices, practical tools, and experience exchange [20].

Practices to support physical health (regular sport activity, healthy eating habits, enough sleep) and social health (networking, creative activities, family support, abilities to say "no", to take a break) can become basic principles of self-healing and recharging energy. Particular attention should be given to stress management programs, coping strategies, and mindfulness. Raising individual and collective awareness of the problem with vital energy should become a principal issue in the global discussion about leadership competencies.

Time and energy efficiency in management is a very significant topic in any branch; it relates company's success and further development. This kind of efficiency is essential in non-profit organizations, environmental and social projects with driven and passionate leaders. Whether the leader communicates changes within community-based or work-based movements, whether his/her activity is a full-time job or voluntary activism - it anyway challenges the leader to follow the work-life balance and find the opportunity to recharge oneself. In other words, in order to drive sustainable changes, leaders should have a sustainable lifestyle.

One of the strategies for recharging energy suggests unplugging from distractions (e.g., time and energy-consuming activities, toxic environment) [21]. Nevertheless, it is crucial not only to know how to deal with the energy loss, burnout, and concomitant loss of motivation, nervousness, and stress; it is essential to be aware of strategies to prevent the development of such conditions [22]. So, both energy loss prevention and energy recharging should belong to the individual and organizational sustainability in order to prevent the destructive influence of the leadership activities.

\section{Conclusions}

Sustainability topics require personal and organizational energy and motivation to promote sustainable goals, to make changes, and motivate the community. Leaders of those activities 
should have enough energy resources to deal with a high rate of responsibility, urgency, overwork, and various obstacles that inhibit changes. However, in a time of rapid transformation, increased demands, and uncertainty, even the most enthusiastic leader, can face some physical or social health problems resulting from work-life disbalance.

This article explained the motivating power of leaders expressed in the vital energy coefficient. This coefficient, together with intelligent and emotional competencies, constructs the leader's ability to overcome challenges and motivate the team. Particularly, in the work of social and environmental activists, whether they get paid or participate voluntarily, there is a danger of losing too much vital energy with no opportunity to recharge oneself. The disbalance of work and life expressed in the loss of energy can result in emotional or professional burnouts followed by some physical or social health problems.

The incorrect use of life and work priorities, as well as various job stressors, weaken the individual's capability to confront burnout. Nevertheless, the in-time stress management practices, implementation of coping strategies, balancing priorities and tasks, and exercises to deal with stress and stressors can facilitate positive changes in individual's emotional and physical conditions. Moreover, those who can efficiently deal with their own vital energy, control personal sustainability, can also negotiate the organizational sustainability by encouraging, stimulating, and preventing the burnout of the team members. Managing vital energy today should become one of the key competencies of modern leaders to promote and support positive changes in sustainable development.

\section{References}

1. V.G. Nemirovskiy, A.V. Nemirovskaya, Monitoring, 4(122), 104 (2014)

2. E.V. Balazkiy, Monitoring, 2(82), 124 (2007)

3. A.S. Rodionov, ActualScience, 2(8), 67 (2016)

4. P. Casse, https://www.forbes.ru/column/48259-glavnoe-kachestvo-lidera-energiya-neintellekt (2010)

5. D.C. Glass, J.D. McKnight, Psychology and Health, 11(1), 23 (1996)

6. C. Maslach, M.P. Leiter, Stress: Concepts, Cognition, Emotion, and Behavior, 4, 351 (2016)

7. D. McDermott, Journal of Human Stress, 10(2), 79 (1984)

8. S.B.N. Evenstad, International Journal of Systems and Society, 2(2), 52 (2015)

9. A. Zopiatis, P. Constanti, International Journal of Contemporary Hospitality Management, 22(3), 300 (2010)

10. S. Oliver, https://www.forbes.com/sites/forbescoachescouncil/2020/05/28/how-leaderscan-save-their-businesses-and-avoid-burnout-at-the-same-time/?sh=21c260df229f (2020)

11. J. Bejtkovský, Marketing and Management of Innovations, 1, 294-302 (2020)

12. A.J. Montgomery, E. Panagopolou, M. de Wildt, E. Meenks, Journal of Managerial Psychology, 21(1), 36 (2006)

13. N. Belyakova, E. Petrova, O. Polyakova, Economic and Social Development: Book of Proceedings; Varazdin, 324 (2017)

14. L. Cox, Into-ebooks, Helsinki, 2011: http://mural.maynoothuniversity.ie/2815/(2011)

15. D.-Y. Jeung, C. Kim, S.-J. Chang, Yonsei Medical Journal, 59(2), 187 (2018)

16. P.C. Gorski, Ethnic and Racial Studies, 42(5), 667 (2019)

17. C.W. Chen, P.C. Gorski, Journal of Human Rights Practice, 7(3), 366 (2015)

18. M. Leiter, Canadian Psychology/Psychologie canadienne, 32(4), 547 (1991)

19. J. Baumgardt, J. Moock, W. Rössler, W. Kawohl, Frontiers in Public Health, 3, 25 (2015)

20. Heinrich Böll Stiftung Moscow, https://ru.boell.org/ru/2020/04/21/ustoychivyyaktivizm-onlayn (2021) 
21. L. Maloney, https://www.forbes.com/sites/forbescoachescouncil/2019/07/22/how-tounplug-from-distractions-and-plug-into-your-own-vital-energy/?sh=2450cac $7 b 7 f 3$ (2019)

22. J. Perlo, D. Feeley, Journal of Healthcare Management, 63(2), 85 (2018) 